\title{
Treatment of Sigmund Freud's Maxillary Jawbone Cancer by Hans Pichler and Varaztad Kazanjian (1856-1939)
}

\section{Xavier Riaud*}

Francois Vieta Centre for the History of Science and Technology (EA 1161), University of Nantes, France

\begin{abstract}
From 1919 to his death, Sigmund Freud was treated for a maxillary jawbone cancer by two exceptional surgeons, the Austrian, Hans Pichler, and the American, Varaztad Kazanjian. Fleeing the Nazi regime, he went into exile in England where he died after numerous recurrences of the disease.
\end{abstract}

Keywords: Cancer; History of medicine; Surgery; Verrucous carcinoma

\section{A Brief Account on Sigmund Freud (1856-1939)}

As the main proponent of psychoanalysis, he analysed the psychic apparatus and processes, especially the concepts of the unconscious mind, dreams and neurosis. He went on to propose treatment techniques and psychoanalytic therapy. Freud united a generation of psychotherapists who progressively developed the practice of psychoanalysis all over the world. Despite internal divisions and criticism from certain psychiatrists as well as the outbreak of World War II, psychoanalysis appeared as a new discipline of social studies from 1920. In 1938, Freud, threatened by the Nazi regime, left Vienna to go into exile in London where he died of cancer in 1939.

\section{Freud's Cancer}

In 1919, Sigmund Freud was first seen by Hans Pichler (1877-1949), an Austrian stomatologist who was considered to be one of the best maxillofacial surgeons in Europe. He consulted him about a painful swelling in the left palate and in the region of the maxillary tuberosity which persisted for a week [1].

Between 1923 and 1938, Pichler operated on the philosopher, who was a heavy smoker, around twenty-five times on the right side of the soft palate, hard palate, palatoglossal arch, oral mucous membrane and the rear mucus membrane of the mandible. On October 4 and 11, he excised a part of the higher jawbone and right palate, ligating the right external carotid artery, and removing the submandibular and cervical lymph nodes. On November 12 1923, he carried out the resection of the pterygoid process and part of the soft palate. The operations were a great success. His recovery was difficult and Freud only started working again in January 1924 [2]. His first prosthesis was fitted in 1923, and he had his fifth palatal obturator made in 1928.

On the day of his seventieth birthday, he exclaimed: "I hate my mechanical jaw". He soon found a parallel regarding his new prosthesis: "Fitting a new prosthesis is like the quest for happiness. You think you have reached it, but before long you realize that everything has to be done again [3]." When he was asked to speak French, he refused saying that: "My prosthesis does not speak French."

In a letter dating back to 23 April 1923, Freud wrote: "Two months ago, I noticed a leucoplasia lump on my maxilla and on my right palate which had already been removed. I am still not working and cannot swallow. I am certain of its non-malignancy but as you know, you can never be totally sure. According to my personal diagnosis, it may be an epithelioma but my colleagues have not confirmed it. Tobacco is the likely cause." Freud started smoking when he was 24 years old and quickly went on to smoking only cigars.

In 1930, Freud made two trips to Berlin where Dr Hermann Schroeder, the head of the Dental Institute of the University of Berlin fitted a first prosthesis. These trips to the capital exhausted the patient. Consequently, for a very brief period, a dentist from Vienna, Dr Joseph Weinmann, undertook his treatment. In both cases, Freud suffered a lot and could not endure the prostheses [4].

In 1931, Dr Brunswick, a close colleague of Freud, decided to help him. Without Freud's knowledge, he called upon Professor Varaztad Kazanjian (1879-1974), an eminent Armenian American dentist and the 20th century forerunner of maxillofacial surgery, to come to Vienna in order to design the philosopher's new prostheses.

Passing through Europe for congresses in London and Paris in 1931, Kazanjian initially refused. Brunswick consequently asked for Princess Maria of Greece's help and she agreed. Kazanjian finally accepted and made a detour through Vienna on July 31 and August 1. He saw the philosopher on those two days at Pichler's dental office. On August 3, Freud wrote in his diary: "Something unbelievable happened! Within a day and a half, the magician made a prosthesis which is less intrusive and heavy than all the others and with which I can chew, talk and smoke like before [3].

With his own hands, he made three prostheses in Pichler's laboratory with the supplies that Princess Maria had sent him. Freud knew that Kazanjian could hardly help him more [5]. At a later date, Kazanjian said to one of his colleagues that there was little hope of the prosthesis being successful. Kaznajian left Vienna on August 29. On August 30 1931, Freud wrote: "The magician left yesterday. I do not feel as great as before but I can speak more easily. It will be difficult to do any more for me [3].

Kazanjian asked for 5000 dollars for his work which were paid. During his stay, Kazanjian stayed only in Pichler's laboratory; he did

*Corresponding author: Xavier Riaud, Francois Vieta Centre for the History of Science and Technology, University of Nantes, France, 145, route de Vannes, 44800 Saint Herblain, France, Tel: 00240766488; Fax: 00240766488; E-mail: xavier.riaud@wanadoo.fr

Received June 22, 2014; Accepted January 08, 2015; Published January 11, 2015

Citation: Riaud X (2015) Treatment of Sigmund Freud's Maxillary Jawbone Cancer by Hans Pichler and Varaztad Kazanjian (1856-1939). J Trauma Treat 4 : 236. doi:10.4172/2167-1222.1000236

Copyright: (c) 2015 Riaud X. This is an open-access article distributed under the terms of the Creative Commons Attribution License, which permits unrestricted use, distribution, and reproduction in any medium, provided the original author and source are credited. 
not see anything of Vienna. He worked night and day and the patient sometimes saw him from three to four hours a day. After a short twenty-day stay, Kazanjian could not return to Vienna again for he had to be near his family [3]. Kazanjian's prostheses helped the famous psychoanalyst for three years [6].

Furthermore, the Austrian dentist saw Freud 143 times between 1923 and 1924, and 122 times from 1926 to 1928 [5]. He was said to have treated him 16 times in 1923, 74 times in 1924 and 94 times in 1932 [7]. In 1938, afraid of the Nazis, Pichler examined Freud one last time before his departure for Austria. He also examined him on September 71938 in London and observed a recurrence of his carcinoma [5]. Freud died of a verrucous carcinoma (also known as Ackerman's tumour) in 1939 when he was 83 years old. With the agreement of his daughter, Anna Freud, he was said to have asked Max Schur, his personal doctor from 1928 to 1938, to inject him with a (lethal?) dose of morphine. Max Schur (1897-1969), an Austrian doctor who also practiced psychoanalysis and who trained in Vienna, was close friends with his famous patient. Indeed, when Freud fled England to escape from the Hitlerian regime, Schur followed. Sigmund Freud never stopped smoking despite his illness. As for Pichler and Kazanjian, they remained friends and never ceased to correspond [8].

\section{Verrucous Carcinoma (also known as Ackerman's Tumour)}

It is a rare histological form of carcinoma, currently recognised as a clinical and independent histopathological entity. It can grow at all membrane levels located in the upper aerodigestive tract but occurs most frequently in oral cavities, followed by laryngeal membranes. Described for the first time in 1948, by Lauren V. Ackerman (19051993), a prestigious American doctor and pathologist who made significant advances in cancer surgery, it represents between 1 and 3\% of laryngeal carcinomas and 2 to $12 \%$ of oral carcinomas. The average age for diagnosis is 69 years old. There is an unquestionable correlation with tobacco consumption and poor oral hygiene. It is a leucoplasic, papillomatous, exophytic and locally aggressive lesion [9].

\section{Hans Pichler (1877-1949)}

The son of a dentist, Hans Pichler was born in Vienna, in $1877 . \mathrm{He}$ gained the respect of his peers through his sporting prowess, both as a teenager and in adulthood. Constantly proving his physical stamina, he excelled in numerous sports, including skiing and alpinism. His pronounced taste for all kinds of physical challenge remained with him throughout his life [10]. After his exploits in the gymnasium, he began medical studies in Vienna, Fribourg and Prague. On August 10 1900, he attended the meeting of the nine founders of the international dental federation (IDF). The next day, due to illness, he could not attend the first meeting of the executive council of the IDF which took place at the Dental School of Paris [11].

That year, he chose to follow a surgical career in the clinic of Anton Eiselsberg. Eiselsberg (1860-1939) was an eminent surgeon from Vienna. Suffering from eczema caused by the antiseptic used to disinfect his hands before each operation. Hans turned towards dental surgery and attended lectures at the Dental School of Northwestern University in Chicago, in 1902. He was tutored by Green Valdimar Black (1836-1915), author of the classification of carious lesions, father of the equally well-known "prophylactic extension" and first dean of the dental school of the university in 1897. Initially, Hans had difficulty adapting to the American teaching approach. However, his scientific pragmatism won through in the end, and he graduated in dentistry at the end of that year. His skill in defending his positions and expressing his opinions soon won him the attention of the best clinicians [1]. The following year, Pichler went back to Vienna where he settled. As a professor, he directed the Dental Institute of the University of Vienna. There, he taught the principles of dental art and oral surgery, and worked towards creating a curriculum for Austrian dentists leading to a diploma.

During the Great War, his work met with remarkable success and he rapidly acquired a rare and renowned dexterity. Pichler's scientific work was colossal; it covered numerous fields of dentistry. He wrote 125 articles and contributed to many books. Focusing his research on maxillofacial surgery and preventive dentistry, he also studied the prostheses which were used after jaw resection, the treatment of trigeminal neuralgia and the management of facial fenestras. $\mathrm{He}$ soon became a great friend of Victor Veau (1871-1949), the famous French surgeon [1]. In 1936, Hans presided over the 9th congress of the International Dental Federation in Vienna. Then a professor, he stated with conviction: "We Austrians want to stay in contact with medicine but we want to collaborate with dentists from all over the world to achieve a common objective." The congress met with resounding success which was a great source of pride for Pichler, in a country where the majority of dentists were stomatologists. During the meeting, two resolutions proposed by Pichler were approved: the end of rivalry between stomatologists and dentists who, he said, should work in perfect harmony, and the obligation for dentists to have followed appropriate medical training in a university [11]. Hans translated Black's book into German and in 1948, he published his three-volume book entitled Surgery of the mouth and jaws (Chirurgie de la bouche et des mâchoires), a collection of his professional experiences [3]. Pichler was a calm man with his own distinct temperament. He was shy, and often came across as reserved and modest. He was an extremely meticulous man who paid attention to the slightest detail. Very tactful, he was kind and caring with his patients and was good at comforting them [1]. Hans Pichler died on February 31949 in Vienna [12] (Figure 1).

\section{Varaztad Hovhannes Kazanjian (1879-1974)}

Varaztad was born on March 18, 1879, in Erzincan, in Turkish Armenia. He did part of his schooling in the French Jesuit Mission of Sivas. In 1893, he moved to Samsun to live with and work for his older half-brother. He later worked in the local post-office. In 1895, he left for the United States where he arrived in October. He lived in the Armenian community of Worcester, Massachusets. He undertook correspondence courses before attending evening classes in Worcester. On October 15 1915, he officially became a US citizen. In 1902, he attended the Boston English High School and went on to attend Harvard School of Dental Medicine. He graduated on June 28 1905. He

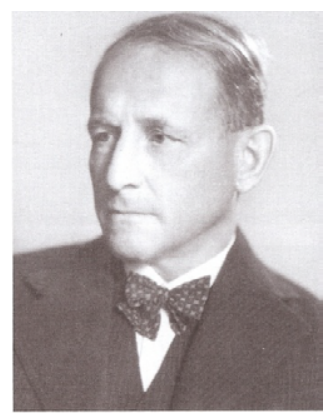

Figure 1: Professor Hans Pichler (1877-1949). 
immediately established his own private dental practice in Boston [3].

In 1906, he was appointed assistant dental technician, then in 1907, assistant in dental prosthetics, and finally in 1909, demonstrator in dental prosthesis at Harvard School of Dental Medicine. In 1911, he began his second year of study in Boston University School of Medicine. In 1912, he was made head of the Prosthetic Dentistry Department at Harvard School of Dental Medicine. In the same year, he left the Boston University School of Medicine. On December 21 1912, he married Sophie Augusta Cuendet in Boston. She died on August 101919.

During World War One, Kazanjian mainly practised as a dentist [3]. In 1915, he was appointed Chief dental officer at the Harvard Medical Unit which was part of the British Expeditionary Forces. He served with the rank of honorary lieutenant. He officiated in Camiers, France at general hospitals no.20 and no.22. In September, he met Dr Hayes in Paris at the Dental Department of the American Ambulance. He worked relentlessly at hospital no.22 where he treated no less than 22 casualties within a month. His prosthetic achievements were innovative and original. Each one was unique. Using dental fasteners wherever possible, he immobilized and held together bone fragments in the case of maxillary fractures, and fixed them harmoniously to the original occlusion. On October, 1915, he returned to the USA. He then went back to England along with a second unit coming from Harvard on November 17. On December 3, he visited Oxford. The same month, he was assigned to general hospital no. 20 which was under English command. When entering the main ward, the wounded would kiss his hand as a token of respect and gratitude. Kazanjian was so innovative that some newspapers wrote editorials about him. His original techniques became benchmark surgical procedures. In April 1916, he was the guest speaker at the American Society in Paris. In June, he was promoted Honorary Major of the Royal Army Medical Corps. On June 15, he submitted an article entitled "Immediate Treatment of Gunshot Fractures of the Jaws" to the British Dental Association. In his article, he gave a list of his treatment protocols as well as a classification of fractures. On November 7, 1917 and April 7, 1918, the Armenian doctor received two commendations signed by Churchill. Kazanjian led a team of six dentists who, despite their small number, tried to bring as much comfort as they could to the wounded soldiers. This was when Varaztad invented the Kazanjian clamp which controlled arterial haemorrhages, the Kazanjian button which was used during the immobilization of jawbones with dental rubber bands and the Kazanjian splint for nasal fractures. On June 3,1918, he was appointed "Companion of the Order of Saint Michael and Saint George". His work became more and more famous. In the same year, he was appointed Professor of Military Oral Surgery at Harvard School of Dental Medicine [3]. In 1919, he was demobilised from the British Army after having treated around 3000 patients. In May he was awarded a military decoration by King George V at Buckingham Palace. Upon his arrival in the USA, he was admitted as a third-year student at Harvard Medical School. He resumed his duties as professor of military oral surgery at Harvard School of Dental Medicine [3]. In 1921, he graduated in medicine. In Boston, he established a private practice specialised in facial plastic surgery, surgical prosthesis and oral surgery. On August 25, 1923, he remarried. In 1931, he was named head surgeon for plastic surgery operations at Massachusetts Eye and Ear Infirmary. At the same time, he became consultant specialized in plastic surgery at Massachusetts General Hospital. In 1932, he received an award from the Rhode Island Dental Society. In 1937, he presided over the American Academy of Dental Science and in 1940, the American Society of Plastic Surgeons. In 1943, he received the Alfred E. Fones Medal from the Connecticut State Dental Society. In 1947, he was appointed honorific lecturer at the University of Pennsylvania, School of Medicine [3]. In 1949, he published his first book co-authored with Dr John Marquis Converse, entitled The Surgical Treatment of Facial Injuries (Le traitement chirurgical des blessures de la face). In 1951, he was congratulated by the American Society of Plastic and Reconstructive Surgery for his leadership and devotion in the organization and development for the practice of plastic surgery. In 1952, Bowdoin College awarded him an honorary degree of Science. In 1953, he was awarded the Honour Key Award by the Academy of Ophthalmology and Otolaryngology. In 1954, he received an award from the American Society of Oral Surgeons and was made Honorary Member of the Chalmers J. Lyons Academy of Oral Surgery at the University of Michigan. In 1956, he received the Honorary Award from the American Society of Maxillofacial Surgeons. That same year, he was awarded the Leonard Wood Memorial Medal, Boston City Hospital Alumni Association and was also made Honorary Member of the Massachusetts Dental Society. In 1957, he was made Honorary Member and received an award from the New England Society of Oral Surgeons. In that same year, he was awarded Honorary Membership at the Worcester Dental Society. In 1959, he received an award from the American Association of Plastic Surgeons. The second edition of his book came out the same year. In 1960, he served as the first President of the New England Society of Plastic Surgeons. In 1962, he received written congratulations from the chairman of New York University for his work [3]. In 1964, he retired from his private practice and stopped his work. In 1966, he became Honorary Fellow of the British Association of Plastic Surgeons in London and in 1967, of the Royal College of Physicians and Surgeons in Glasgow. That same year, he was honoured with the Harvard Dental Centennial Award, an achievement illustrating a century of dentistry in Harvard. He died on October 19, 1974, at his home in Belmont, surrounded by his family [3]. Kazanjian was a simple, humble and humanistic man who was close to his family, faithful in friendship and passionate about his work, although he enjoyed nature and fishing above everything. He was adulated by his students but also by his colleagues. He never denied his Armenian origins yet served his new American nation with all his spirit. Kazanjian was internationally known as the pioneer of maxillofacial surgery in the 20th century. Kazanjian was described by his patients and colleagues as a scalpel virtuoso. When his death was announced, medical and media organizations paid tribute to Kazanjian and continued to do so for many years after he died. He submitted 154 publications in American, British, French (7), Spanish (2) and German (1) journals from 1911 to 1975, the last one being posthumous. Among them, there are 50 scientific collaborations. He worked in 18 clinics and hospitals. He taught orthodontia at Harvard Forsyth Post-graduate of Orthodontia (1919-1920), Otolaryngology at the Tufts College Medical School in 1944. He was professor of Oral Surgery at Harvard Medical

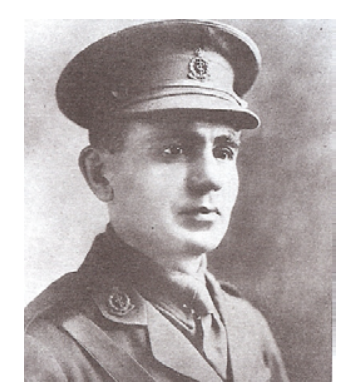

Figure 2: Professor Varaztad H. Kazanjian (1879-1974). 
Citation: Riaud X (2015) Treatment of Sigmund Freud's Maxillary Jawbone Cancer by Hans Pichler and Varaztad Kazanjian (1856-1939). J Trauma Treat 4: 236. doi:10.4172/2167-1222.1000236

Page 4 of 4

School in 1922 and professor of plastic surgery at Harvard Medical School in 1941. He was appointed professor emeritus of plastic surgery at the Harvard Medical School in 1947 [3,12] (Figure 2).

\section{References}

1. Deranian HM (2007) Miracle Man of the Western Front Chandler, Chandler House Press, Worcester.

2. Ennis J (1967) The Story of the Fédération dentaire international 1900-1962 Fédération Dentaire Internationale London.

3. Folz B J, Ferlito A, Weir N, Pratt LW, Rinaldo A, et al. (2007) A historical review of head and neck cancer in celebrities. J Laryngo Otol 121: 511-520.

4. Francis A (2009) Personal communication. Countway Library of Medicine, Harvard Medical Library, Boston USA.

5. Hardt N Sigmund Freud, his oral neoplastic disease and oral, maxillary, and facial surgery", AO Dialogue 6-9.
6. http://www.armeniapedia.org (2006) Varaztad Kazanjian, 1-3.

7. Kremer R Sigmund Freud's agony (1920-1939) 1-3.

8. Montjean F, Evrard L, Magremanne M, Vervaet C, Louryan S, et al. (2004) Oral verrucous carcinoma. Rev Med Brux 25: 173-177.

9. Osterreichische Nationalbibliotek (2009) Personal communication. Picture Archive, 203340-C, Vienna, Austria.

10. Riaud X (2010) The pioneers of maxillofacial surgery. L'Harmattan (edn) Medicine through the centuries collection, Paris.

11. Romm S, Luce EA (1984) Hans Pichler: Oral surgeon to Sigmund Freud. Oral Surg Oral Med Oral Pathol 57: 31-32.

12. Teymoortash A, Silver CE, Rinaldo A, Cardesa A, Folz BJ, et al. (2013) Verrucous carcinoma: a retrospective diagnosis in three historic patients. Eur Arch Otorhinolaryngol 271: 631-633. 